\title{
HYDRAULIC CYLINDER CAD DESIGN SYSTEM BASED ON PRODUCT DISPOSITION
}

\author{
Yigang $\mathrm{Hu}$, Yonggang Shen \\ Shanghai University of Engineering Science, Shanghai, China;Email:hgg163@sohu.com
}

\begin{abstract}
To adapt the requirements of the mass product-made production model, the three-dimension parametric design software about hydraulic cylinder CAD is developed. This software possesses the product disposition function for the product series design with product data management (PDM) basic idea. This design system is more useful to the mass product-made production for the customer requirements (MC, Mass Customization).
\end{abstract}

Key words: Hydraulic Cylinder, Parametric Design, Product Disposition, MC.

\section{INTRODUCTION}

Since the requirements of the persons for the products are going forward the variety and the individuality, the tasks of the enterprise research and developing are more and more heavy. According to the developing experiments of the enterprise new products, for one kind of new product there are $80 \%$ parts and components that are carried on composing and promoting. The enterprise should change its design concept, do its best to use the ripe technology of the old products and to use the machining plants, and do its best to use now available parts to compose more new products. The enterprise should convert the production model of many kinds and small quantity to the production model of many kinds and mass quantity, i.e. the mass product-made production (MC, Mass Customization).The mass product-made production importantly adapts the product disposition design model. This design method is forward product series, can lower the design cost and the production cost, and can short the design period.

This project is supported by Shanghai education committee science and technology development fund.No.03FK 17

Please use the following format when citing this chapter:

$\mathrm{Hu}$, Yigang, Shen, Yonggang, 2006, in International Federation for Information

Processing (IFIP), Volume 207, Knowledge Enterprise: Intelligent Strategies In Product Design, Manufacturing, and Management, eds. K. Wang, Kovacs G., Wozny M., Fang M., (Boston: Springer), pp. 658-663. 
At present, the old CAD software does not possess the function of product disposition, lacks the means of repeatedly using design information sources, and can not adapt the enterprise requirements of the mass product-made production model. Although using PDM technology can satisfy the requirements of product disposition, implementing PDM, the period is long, the cost is high and the risk is big. As one kind of standard PDM system is implemented one year and more in the enterprise, the expenses are up to several 100000 dollars of RMB-1000000 dollars of RMB apart from the expenses of the software and the solid ware. Considering the present cases of Chinese enterprises, particularly the middle enterprises and the small enterprises can not undertake these expenses. Hence facing to these enterprises, developing the CAD software that possesses PDM feature for the product series design possesses the important real significance.

\section{GENERAL SCHEME OF HYDRAULIC CYLINDER CAD SYSTEM}

Hydraulic cylinder is the most usual component of executing in hydraulic system. It is widely applied in common machinery, engineering machinery, lifting and transport trades etc. The chief parts and the chief components of hydraulic cylinder include cylinder lid, cylinder body, cylinder base, piston, piston rod, piston ring, guide sleeve etc. There are many kinds of the structure shape for every kind of part. There are many kinds of series dimension for the part of same structure shape. And there are many kinds of type in the link fashion and the seal fashion.

Firstly for hydraulic cylinder series products of the enterprise, according with the design method facing to product series, we sum up and conclude the product basic prototype (BP), construct the product databases, pick up the change-pattern parameters as the three-dimension templates of series product design and change-pattern design. On the parametric base, the series products are formed. Then according with the requirements of the customer, go on disposing of the product, so that form the new products under satisfying the definite constraint conditions.

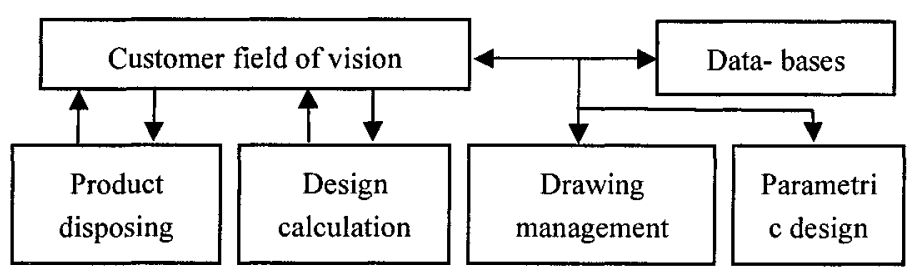

Figure1. General scheme flow diagram. 


\section{GENERAL SCHEME PROTOTYPE SELECTING OF HYDRAULIC CYLINDER}

Under the production model of the mass product-made, from the point of view of constructing prototype of hydraulic cylinder product series, we analyze, sum and conclude the series products of the hydraulic cylinder enterprises, design three kinds of basic structure shape, i.e. clamping key link, flange link and crew link. Through system mutual effect between the person and the computer, select the link between the cylinder lid and the cylinder body, the link between the piston rod and the piston edge, the link between the cylinder base and cylinder body, and select the basic structures of the seal fashion of hydraulic cylinder parts and hydraulic cylinder components. We also should input the requirements of the customer, e.g. the stroke of hydraulic cylinder, the installation dimension, the piston force and the rated press of hydraulic cylinder. Then the general scheme design of hydraulic cylinder is completed.

\section{PARTS AND COMPONENTS STRUCTURE DIMENSION DESIGN OF HYDRAULIC CYLINDER}

According with the structure information of hydraulic cylinder parts and hydraulic cylinder components, under satisfying these conditions of the strength, the stability, the machining technology and the fixing requirement, this system can automatically calculate the structure dimensions of the structure parts, and can store the design parameters of hydraulic cylinder product into the product engineering databases. In the design process of hydraulic cylinder parts and hydraulic cylinder components, this system simultaneously goes on function calibrating about the strength and the stability, checks how the design scheme satisfies the design requirements. If the design scheme can not satisfy the design requirements, this system sends out a warning, and may return and again goes on mending for the structure shape and the structure dimension. Design calculation flow is as follow, first, from customer land mould into strength check mould, if it satisfies the requirement, then into whole scheme select mould and stability check mould, or back into strength check mould. If strength check and stability check are satisfied, then into part component select mould, or back into whole scheme select mould. All of these data are sent into hydraulic cylinder databases. Databases management is controlled by this CAD design system. 


\section{THREE-DIMENSION PARAMETRIC PROTOTYPES DATABASES}

According with the basic shapes of clamping key link, flange link and crew link of hydraulic cylinder, we construct the three-dimension parametric prototypes databases of facing to hydraulic cylinder product series, include and sum the design important parameters of hydraulic cylinder parts and hydraulic cylinder components. Using the design important parameters controls the geometry dimensions of the parts and the developing relations. This system realizes the three- dimension parametric design of hydraulic cylinder through picking up the important parameters of the three-dimension parametric prototypes, and again vests with the values.

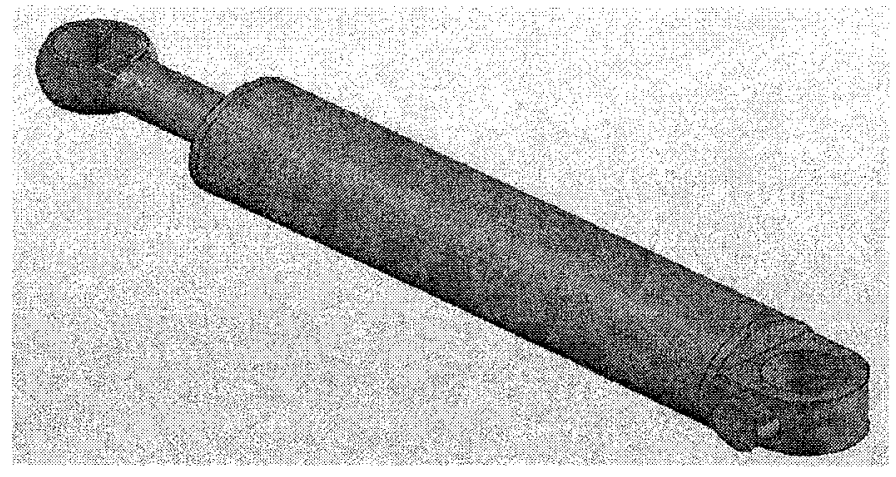

Figure 2. Hydraulic cylinder fixed drawing.

\section{FILES MANAGEMENT}

After completing the product design of hydraulic cylinder, this system automatically places the design parameter data files of the product and the three-dimension drawing data files into the product engineering databases. This system can dimly inquire to the product engineering databases, or set inquiring conditions to look for hydraulic cylinder series product of conforming to the requirements.

File management not only can inquire the parameter data of the product, but also can inquire the three-dimension drawing data of the product using OLE (objective link embed) technology. 


\section{PRODUCT DISPOSITION}

Considering the drawing numbers of the product parts and the product components as the index, forms the layers structure tree of the product. The joint of the tree root represents the product. The joints of the second layer represent the parts and the components. The joints of the third layer represent the standard parts and the seal parts. This method with drawing view reflects the layers relations between the product parts and the product components. Each joint of the structure tree links the related properties of the part and the component, it becomes the shining relation with the alphabetic string of the product databases. Through the joints of the structure tree, we can inquire the design file of the related parts and the related components. According with disposing regulation, we construct the structure tree of the product in the definite scope of the design parameters, complete the product disposition through disposing for the joints of the structure tree, and for disposing product may be out shape design using OLE technology under UG surroundings.

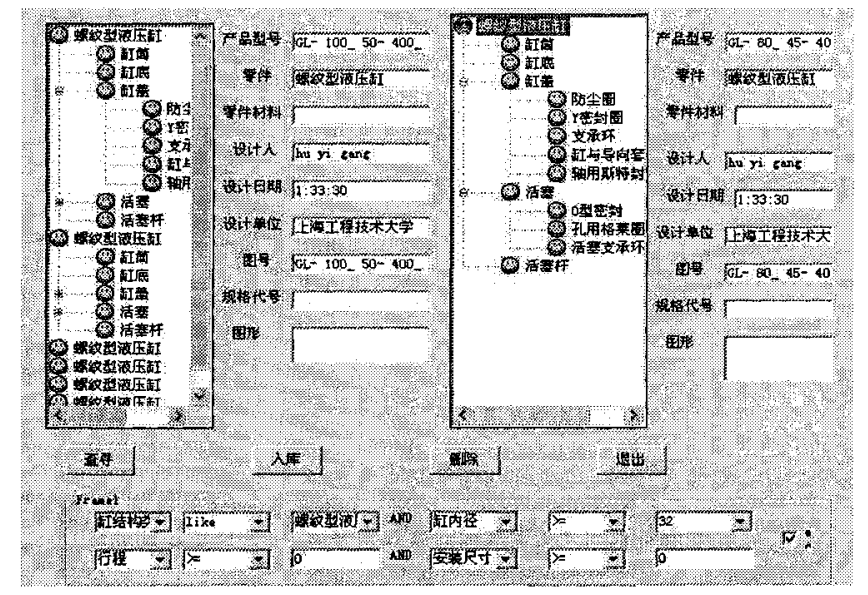

Figure 3. Disposition field of vision.

\section{ENGINEERING DATABASES MANAGEMENT}

Hydraulic cylinder is a product of more standardization and more regularization. In design process, we index the structure dimensions and the specifications numbers about $\mathrm{O}$ pattern seal ring, $\mathrm{V}$ pattern and $\mathrm{Y}$ pattern seal ring, anti-dust ring, spindle and hole composing seal, support hoop and guide hoop. We place various marks of the materials and related mechanics function targets, and the design parameters of standardization and 
regularization into the engineering databases. This system can inquire, index, mend, erase and add information to the engineering databases.

\section{CONCLUSION}

1. Realize CAD parametric design method facing to the product series.

Analyze hydraulic cylinder series products, go on product forecasting for the requirements of the available customers, design the basic prototype (BP) of hydraulic cylinder series products, then pick up the shape parameters considering the three-dimension constraints and the geometry constraints of the product parts and the product components. Based on the mould driving technology, construct the three-dimension parametric mould databases, and realize CAD parametric design and shape design facing to the product series.

2. Support MC product disposition.

Through product disposition, the enterprise does its best of using the product information sources, controls the part kinds and the part quantity into full limitation to dispose more product kinds with less part quantity, forms $\mathrm{MC}$ production model, increases the design efficiency, decreases the production cost.

3. Embed file management and engineering databases management in CAD design.

This system can store and inquire to design parameter files and drawing data files. This system also can inquire, index, mend, erase and add to the engineering databases.

4. Design and property checking calculation simultaneously treating.

At the same time of design, this system can automatically go on calculating and checking about the strength and the stability to judge if the design scheme and the part structure dimension satisfy the property regulations. If they can not, this system puts forward the warn information.

\section{REFERENCES}

1. Ren Jian-ping, Li Ju, (2004), Research on Heterogeneous Environment of Engine CAD Engineering Databases, Journal of Shanghai University, Vol. 8, Suppl.,pp.149-151.

2. Zhuang Pin, Wang Ning-sheng,(2003), Research on Supply Chain Management for Mass Customization, Aeronautical Manufacturing Technology, Vol. 7,pp.46-47.

3. Hu Dian-wei,Zhang Xu,Zhang Xu-hui(2005), Management of Standard Part Library Based on PDM, Aeronautical Manufacturing Technology,Vol. 2,pp.85-88.

4. Gu Yong,Chen Wei et al,(2005), Parametric Design of Drawing Die Structure for Auto Cover Panel Based on UG, Aeronautical Manufacturing Technology, Vol. 3,pp.75-77.

5. Lu Ji-ping, Tang Shui-yuan, Yan Yan, (2005),PDM-Based Integrating Technology, Aeronautical Manufacturing Technology, Vol. 4,pp.96-97. 